\title{
The epidemiology of sports and exercise related injury in the United Kingdom
}

\author{
J P Nicholl, P Coleman* and B T Williams $†$ \\ Director, Medical Care Research Unit, University of Sheffield, *Research Associate, Medical Care Research Unit, \\ University of Sheffield and +Professor of Public Health Medicine, University of Sheffield, Sheffield, UK
}

\begin{abstract}
A national study of exercise related morbidity (ERM) in England and Wales was carried out using a postal questionnaire sent to 28857 adults aged $16-45$ years. The questionnaire asked about regular participation in sports or other recreational fitness activities involving physical exercise, and for details of any injuries occurring during a $28 \mathrm{~d}$ reference period. A return rate of $68 \%$ was achieved. Comparisons with other national data sources indicated that the information obtained was reliable. It is estimated that each year there are 29 million incidents resulting in new or recurrent injuries, however minor, of which 9.8 million (95\% confidence interval 8.1 to 11.4 million) result in new 'substantive' injuries which are potentially serious, result in treatment, or in participants being unable to take part in their usual activities. Soccer accounted for more than $25 \%$ of all ERM, but the risk of a substantive injury in rugby was three times that in soccer. Over one third of ERM occurred in men aged 16-25 years. The most frequently reported injuries were sprains and strains of the lower limbs. Treatment was sought in approximately $25 \%$ of ERM incidents and $7 \%$ of all new ERM incidents involved attendance at a hospital accident and emergency department. The treatment provider most likely to be consulted was a general practitioner, but physiotherapists and complementary medicine practitioners were also consulted frequently. To maximize the health benefits of exercise, research strategies to reduce the volume and severity of ERM and to identify the most appropriate ways of managing ERM should be set.

(Br J Sports Med 1995; 29: 232-238)
\end{abstract}

Keywords: epidemiology; exercise rates; injury incidence ; injury risk; postal questionnaires

The health benefits of exercise, both for the individual and society, in terms of reducing the risks of certain diseases, and in conferring feelings of mental and physical wellbeing, are well documented, ${ }^{12}$ and the evidence has encouraged those involved in public health programmes to recommend less sedentary lives. In 1979 the United States set a national health objective of having at least $60 \%$ of adults aged 18-64 years participating in regular exercise by $1990 .^{3}$ The World Health Organization European Region's Health for All target number 16 requires member states to set clear

Address for correspondence: Professor J P Nicholl, Medical Care Research Unit, SCHARR, University of Sheffield, Regent Court, 30 Regent Street, Sheffield Si 4DA, UK targets for 'appropriate physical activity' by $1995 .{ }^{4}$ Information available in the United Kingdom indicates an increasing trend for the adult population to take part in leisure time physical exercise. ${ }^{5} \mathrm{~A}$ survey in England in 1991 estimated that approximately $44 \%$ of men and $40 \%$ of women were taking some form of regular physical exercise and although the exercise involved may not be of the type, duration, and intensity required to moderate the risk of coronary heart disease, ${ }^{\circ}$ participation in exercise is welcomed as a way of contributing to improving the health of the nation.

There is a reluctance, however, to recognize that increased participation in sports and exercise will also result in an increase in exercise related injuries. The risks of exercise have been referred to as '... irrelevant to the majority of the exercising public'.6 This opinion is perhaps understandable because, until recently, little was known about the extent and nature of exercise related morbidity (ERM). Studies of sports injuries have typically focused on clinical case series, ${ }^{78}$ accident and emergency department (A and E) caseload, ${ }^{910}$ sports injury clinics, ${ }^{11}$ or on specific sports, ${ }^{12-14}$ or populations, ${ }^{15}$ and such studies cannot provide the information necessary to inform public health policies nor can they reliably enable measurement of risk and the development of effective prevention strategies. With some exceptions from abroad, few epidemiological studies have been carried out from a general population perspective,,$^{1617}$ and representative national information for the UK population about ERM has not been available. The Leisure Accident Surveillance Systems $(\text { LASS })^{18}$ is restricted to attendances at accident and emergency departments, while the General Household Survey $(\mathrm{GHS})^{19}$ has included questions on sports accidents but only for those resulting in contact with a doctor. A national study of the epidemiology of ERM in England and Wales was therefore commissioned by the Sports Council. The aims of the study were to provide reliable estimates of the annual incidence and patterns of ERM, to describe the nature and severity of injuries, compare risks for different activities and examine what factors may affect risk, and also to provide estimate of the costs. The results are available in the form of a full technical report ${ }^{20}$ but in order to make these more widely available, some of the results relating to national estimates of the incidence and patterns of ERM occurring in vigorous activities are presented here. 


\section{Methods}

This study was undertaken over a four year period between 1987 and 1990. A pilot study to test the reliability of the methodology proposed for the national survey was carried out during 1987 and 1988 and the results have been reported previously. ${ }^{21}$

The main study was conducted during 1989 and 1990. Postal questionnaires were sent at one month intervals between July 1989 and June 1990 to a random sample of approximately 29000 persons aged between 16 and 45 years resident in England and Wales. The age range of the population was changed from 16-64 in the pilot to 16-45 years in the main study as the pilot study ${ }^{21}$ indicated a rapid decline in the self reported injury rate in older adults.

A multistage stratified random sample was selected. All the Family Practitioner Committees (FPCs) (now known as Family Health Services Authorities) in England (with the exception of the two selected in the pilot study) and those in Wales were assigned into 18 regional and socioeconomic groups, ${ }^{22}$ and one FPC from each group was sampled. Sixteen agreed to take part. There were 4466 general practitioners (GPs) in the participating FPCs and to ensure a balanced sample each month, these were assigned into 12 monthly groups on the basis of their practice list sizes and geographical location. A variable sampling fraction was then used to yield a target sample of approximately 2150 patients from each FPC (approximately 34400 in total). With the consent of their GPs, approximately 29000 adults were mailed questionnaires and up to two reminders during the month to which their respective GP has been assigned.

The questionnaire developed in the pilot study used a 28 day reference period and was divided into three sections: participation, injury experiences, and some general background and lifestyle questions which asked about age, weight and height, smoking and drinking habits, education, employment, and family support. The section on participation requested information about '... sports or other recreational fitness activities involving physical exercise'. The wording was designed to encourage reporting of non-vigorous activities to ensure that all vigorous activity would be reported. Similarly to ensure full reporting of all injuries occurring during the reference period, the section of ERM asked for details of '... any injury or illness, however minor, through taking part in any of the activities [you] listed...'. As there is no way to measure the severity of injuries reported briefly on a questionnaire, proxy measures of severity were introduced, adapted from definitions of injury developed in the US national electronic injury surveillance systems (NEISS) ${ }^{23}$ and the national athletic injury/illness reporting system $(\text { NAIRS })^{23}$ also in the United States. The 'trivial' injuries were separated out from those which were potentially more serious (substantive injuries)-identified as those which restricted the participant from taking part in usual activities (including days off work) for at least one day, and those for which treatment had been sought. All injuries to the head, face, and features were also classified as 'substantive'. The section of the questionnaire relating to injury experiences also contained prompts to distinguish 'new' incidents from those which were 'recurrences' of ERM originally sustained outside the 28 day reference period.

\section{Statistical methods}

At the time of the survey the population of England and Wales aged between 16 and 45 years was approximately 23 million. Responses were weighted separately within each FPC sample to allow for demographic and geographical differences in the response rates and the stratification, and multiplied up to yield estimates for the whole population. Annual estimates of the numbers of injury incidents were obtained by multiplying the national estimates for the four-week reference periods by 13. All percentages reported in the text and tables are based on the relevant weighted estimates (tables of weighted frequencies do not necessarily sum exactly to the totals given in the tables because of rounding errors in the weighted numbers).

Standard errors and $95 \%$ confidence intervals $(95 \%$ CI) for certain key estimates have been calculated using the methods detailed by the Office of Population Censuses and Surveys (OPCS) ${ }^{24}$ for surveys such as this. Statistical tests comparing rates have been carried out by fitting standard log-linear Poisson regression models to the data and relating changes in deviance to $\chi^{2}$ distributions. ${ }^{20}$

\section{Results}

Almost three quarters of the $4466 \mathrm{GPs}(72 \%)$ agreed to take part and 28857 adults registered as their patients were sent questionnaires. Of these, 2408 questionnaires were returned undelivered by the Post Office, a rate of $8.3 \%$ which is lower than reported in previous studies. ${ }^{25-27}$ Excluding the 'return to senders' who did not receive the questionnaire and therefore did not have the opportunity to respond, $68 \%$ of the 26449 adults who may have received their questionnaires responded. The response rate was less than in the pilot study, ${ }^{21}$ probably because of the effect of difference in the age of the two study populations. However, despite variations in the methods of data collection and coding, the participation rates obtained in the study are very similar to those of the GHS, ${ }^{19}$ indicating that the estimates obtained from the study are reliable (Table 1).

\section{Annual estimates of injury incidents}

There were 17564 usable questionnaires returned. In these, 7829 responders $(44.6 \%)$ reported taking part in vigorous activities and $1429(8 \%)$ reported 1705 incidences of ERM (1094 new incidents and 611 recurrences of an injury from previous incident) resulting in a total of 1803 injuries, during the previous four weeks. This gives annual estimates of 19.3 million incidents $(95 \% \mathrm{CI} 17.0-21.6)$ resulting in new injuries and an additional 10.4 million incidents of recurring ERM conditions in the adult population of England and 
Table 1. Classification of sports and activities and \% of population aged 16-45 years participating in the previous 4 weeks

\begin{tabular}{|c|c|c|c|}
\hline \multirow[b]{2}{*}{ Activity } & & \multicolumn{2}{|c|}{$\begin{array}{l}\% \text { participating in } \\
\text { previous } 4 \text { weeks }\end{array}$} \\
\hline & & $(1989 / 90)$ & GHS (1987) \\
\hline \multicolumn{4}{|l|}{ Vigorous sports } \\
\hline \multicolumn{4}{|l|}{ 'Ball' games } \\
\hline Soccer & Association football, 5-a-side, 7-a-side & 10.0 & 8.7 \\
\hline Badminton & & 4.9 & 5.6 \\
\hline Cricket & & 2.0 & 2.1 \\
\hline Rugby & Union, League & 1.0 & 0.7 \\
\hline Squash & & 4.9 & 4.5 \\
\hline Tennis & & 2.7 & 2.9 \\
\hline Hockey & & 0.9 & 0.3 \\
\hline Basketball & & 0.5 & 1.1 \\
\hline Netball & & 0.7 & 0.8 \\
\hline Other ball games & $\begin{array}{l}\text { American football, ice hockey, nipsy, rounders, hurling, lacrosse, } \\
\text { shinty, baseball, softball, racquet ball, korfball, stool ball, fives, } \\
\text { volleyball }\end{array}$ & 1.2 & 0.0 \\
\hline \multicolumn{4}{|l|}{ Other vigorous sports } \\
\hline Athletics & Track/field, unspecified & 0.2 & 0.9 \\
\hline Gymnastics & Gymnastics, trampolining & 0.6 & \\
\hline Martial arts & Judo, karate, kung fu, tae kwon do, boxing, wrestling & 1.4 & 1.7 \\
\hline Climbing & Abseiling, climbing walls, mountaineering & 0.2 & 0.1 \\
\hline \multicolumn{4}{|l|}{ Vigorous activities } \\
\hline Running (not track) & Jogging, running, marathon, cross-country, orienteering & 7.2 & 8.8 \\
\hline Horse riding & $\begin{array}{l}\text { Cross country trials, horse riding, jumping, polo, pony riding, } \\
\text { dressage/training }\end{array}$ & 1.5 & 1.5 \\
\hline Weight training & Multi-gym, weight lifting, weight training & 6.7 & 8.0 \\
\hline Swimming and diving & Diving, swimming indoors, outdoors & 15.9 & 19.9 \\
\hline Keep fit & Aerobics, keep fit, yoga, rowing machine, exercise bike, acqu fit & 12.4 & 11.7 \\
\hline Water sports & $\begin{array}{l}\text { Boating, canoeing/kayak, water skiing, windsurfing, sailboarding, } \\
\text { yachting, hydroplaning, rowing, sailing, canoe, polo, rafting, jet } \\
\text { skiing, surfing, sculboarding, dragonboat racing }\end{array}$ & 1.5 & \\
\hline
\end{tabular}

Table 2. National annual estimates of substantive and non-substantive incidents of exercise related morbidity (ERM) in vigorous sports and activities

\begin{tabular}{|c|c|c|c|c|}
\hline & \multicolumn{2}{|c|}{ New } & \multicolumn{2}{|c|}{ Recurrent‡ } \\
\hline & Sample numbers & Estimate (millions) & Sample numbers & Estimate (millions) \\
\hline Fractures, dislocations, and head injuries & 106 & 1.8 & 23 & \\
\hline Additional treated incidents* & 239 & 4.4 & 180 & \\
\hline \multicolumn{5}{|l|}{ Additional restrictive incidentst } \\
\hline off work & 19 & 0.3 & 25 & \\
\hline off sport & 179 & 3.1 & 106 & \\
\hline All substantive ERM & 543 & 9.8 & 334 & \\
\hline $95 \% \mathrm{Cl}$ & & $8.1-11.4$ & & \\
\hline Non-substantive injuries & 551 & 9.6 & 277 & \\
\hline All ERM & 1094 & 19.3 & 611 & 10.4 \\
\hline $95 \% \mathrm{Cl}$ & & $17.0-21.6$ & & $8.7-12.1$ \\
\hline
\end{tabular}

*Additional to incidents resulting in fractures, dislocations, or head injuries.

tAdditional to incidents resulting in fractures, dislocations, or head injuries and treated incidents.

$\ddagger$ Annual estimates for recurrent injuries could not be reliably split into substantive and non-substantive because of ambiguity about

whether treatment and restriction of activity related to the recurrence or a former occurrence.

Wales. Approximately one half of all new incidents of ERM were classified as 'substantive' (Table 2).

\section{Activities involved}

More than one quarter $(28.9 \%)$ of all new incidents of ERM in vigorous activities occurred in soccer, and no other single popular activity accounted for more than $10 \%$. This translates into estimates of 8.6 million incidents of ERM from soccer annually among the adult population in England and Wales. Three 'fitness' activities (other running, weight training, and keep fit), each responsible for more than two million incidents annually, contributed the largest proportion of incidents after soccer (Figure 1).

\section{Risk}

In 13 popular activities in which there were sufficient numbers of injuries for the risk to be estimated reliably, rugby with a self-reported injury rate of 96.7/1000 occasions of participation had the highest risk of any 
Injuries in sport and exercise: J P Nicholl et al.

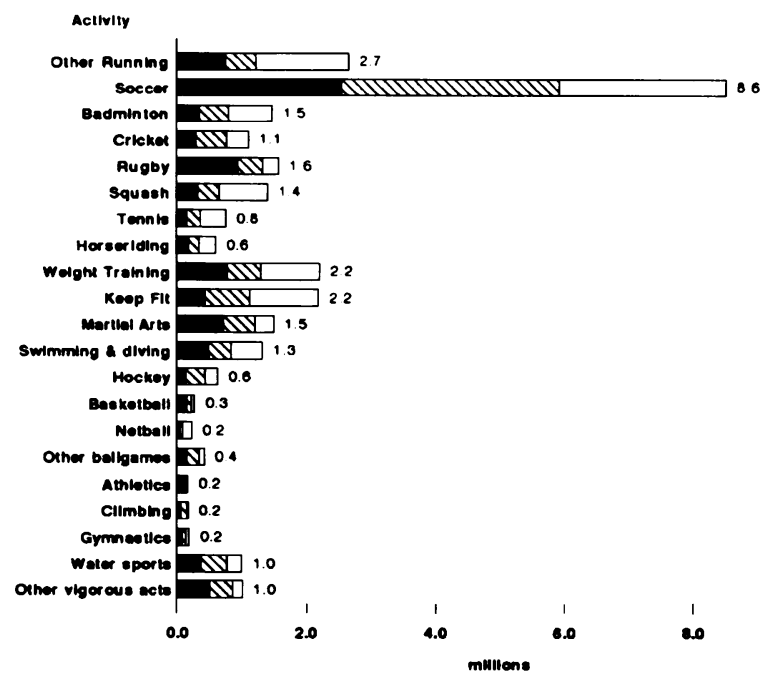

Figure 1. National annual estimates of exercise related morbidity by activity

New substantive

$\mathbb{\nabla}$ New non-substantive

$\square$ Recurrent

Table 3. Risk of exercise related morbidity per 1000 occasions of participation

\begin{tabular}{|c|c|c|c|}
\hline \multirow[b]{2}{*}{ Activities } & \multirow[b]{2}{*}{$\begin{array}{c}\text { All } \\
\text { incidents }\end{array}$} & \multicolumn{2}{|c|}{$\begin{array}{c}\text { New substantive injury } \\
\text { incidents }\end{array}$} \\
\hline & & All & $\begin{array}{l}\text { Excluding } \\
\text { incidents } \\
\text { resulting in } \\
\text { time off } \\
\text { sport }\end{array}$ \\
\hline Rugby & 95.7 & 57.7 & 50.0 \\
\hline Soccer & 64.4 & 19.5 & 13.2 \\
\hline Hockey & 62.6 & 13.9 & 11.6 \\
\hline Cricket & 48.7 & 13.7 & 11.9 \\
\hline Badminton & 28.7 & 7.1 & 3.2 \\
\hline Squash & 23.9 & 5.6 & 4.8 \\
\hline Tennis & 23.1 & 5.0 & 1.9 \\
\hline Other running & 15.3 & 4.5 & 2.4 \\
\hline Weight training & 11.9 & 4.2 & 1.9 \\
\hline Keep fit & 7.7 & 1.5 & 0.7 \\
\hline Martial arts & 45.0 & 22.3 & 15.2 \\
\hline Horseriding & 16.6 & 5.2 & 4.2 \\
\hline Swimming/diving & 6.1 & 2.3 & 1.9 \\
\hline
\end{tabular}

ERM (Table 3). The risk of ERM in soccer with a rate of $64.4 / 1000$ occasions, which was similar to field hockey (62.6/1000 occasions), is approximately $50 \%$ less than in rugby. The difference in risk between rugby and other activities was greater for substantive injury incidents (rugby 57.7/1000 occasions compared to $22.3 / 1000$ occasions in martial arts and 19.5/1000 occasions in soccer). Excluding those injuries which resulted only in a restriction of participation in the sport for at least one day, the difference was still wider with the risk of injury in rugby nearly four times the risk in soccer.

\section{Age and sex of the injured}

Numerically, $50 \%$ of all substantive incidents of injury occurred in the age group 16-25 years and $75 \%$ were
Table 4. How incidents resulting in substantive injury occurred

\begin{tabular}{|c|c|c|c|c|}
\hline \multirow[b]{2}{*}{$\begin{array}{l}\text { How the injury } \\
\text { occurred }\end{array}$} & \multicolumn{2}{|c|}{ New } & \multicolumn{2}{|c|}{ Recurrent‡ } \\
\hline & $\begin{array}{l}\text { Sample } \\
\text { numbers }\end{array}$ & $\%$ & $\begin{array}{c}\text { Sample } \\
\text { numbers }\end{array}$ & $\%$ \\
\hline \multicolumn{5}{|l|}{ Extrinsic } \\
\hline Stuck by ball & 28 & 5.0 & 2 & 0.6 \\
\hline $\begin{array}{l}\text { Struck by other } \\
\text { object }\end{array}$ & 18 & 3.6 & 13 & 4.0 \\
\hline Fall & 48 & 8.8 & & \\
\hline $\begin{array}{l}\text { Collision with } \\
\text { furniture }\end{array}$ & 55 & 9.9 & 9 & 2.6 \\
\hline $\begin{array}{l}\text { Collision with } \\
\text { person(s) }\end{array}$ & 140 & 28.0 & 22 & 7.5 \\
\hline $\begin{array}{l}\text { Intrinsic } \\
\text { Not known }\end{array}$ & $\begin{array}{r}249 \\
5\end{array}$ & 44.7 & $\begin{array}{r}281 \\
7\end{array}$ & 85.3 \\
\hline All & 543 & 100 & 334 & 100 \\
\hline
\end{tabular}

$\mp$ See table 2 footnote

Table 5. Nature of exercise related morbidity occurring during vigorous activities

\begin{tabular}{lcc}
\hline Nature of injuries & $\begin{array}{c}\text { Sample } \\
\text { numbers }\end{array}$ & $\%$ \\
\hline Cuts and lacerations & 74 & 4.3 \\
Abrasions & 50 & 3.3 \\
Dislocations & 41 & 1.8 \\
Fractures & 37 & 1.8 \\
Sprains and strains & 859 & 45.3 \\
Contusions & 224 & 12.2 \\
Tenderness, swelling, blisters & 33 & 2.3 \\
Burns & 18 & 1.1 \\
Concussion & 5 & 0.3 \\
Unspecified pain & 297 & 17.6 \\
Other & 52 & 2.9 \\
Illness & 88 & 5.7 \\
Unspecified injury & 25 & 1.4 \\
Total & 1803 & 100 \\
\hline
\end{tabular}

sustained by men. However, in those activities which could be compared there was no evidence of any difference in injury rates between men and women, except in horse riding, where the risk in men was almost twice that in women. ${ }^{20}$ Comparing rates for the age groups (16-25, 26-35, 36-45) showed little evidence of a changing risk with increasing age $\chi_{1}^{2}=1.6, P>0.1$ ), except again in horse riding, where there was some indication of an increasing risk with increasing age. ${ }^{20}$

\section{How injuries were sustained}

Just over half the 877 substantive incidents in vigorous activities $(55 \%)$ had causes which were external to the player. Collisions with other players accounted for almost half of all these extrinsic injuries (Table 4). Sixty one injuries $(7 \%)$ resulted from players being struck by balls, racquets, or similar equipment, and cricket accounted for one third of injuries caused by these means and half of all the ERM resulting from being struck by balls. In contrast, $84 \%$ of recurrent injury incidents had intrinsic causes which did not result from any influences which were external to the participant (Table 4). 


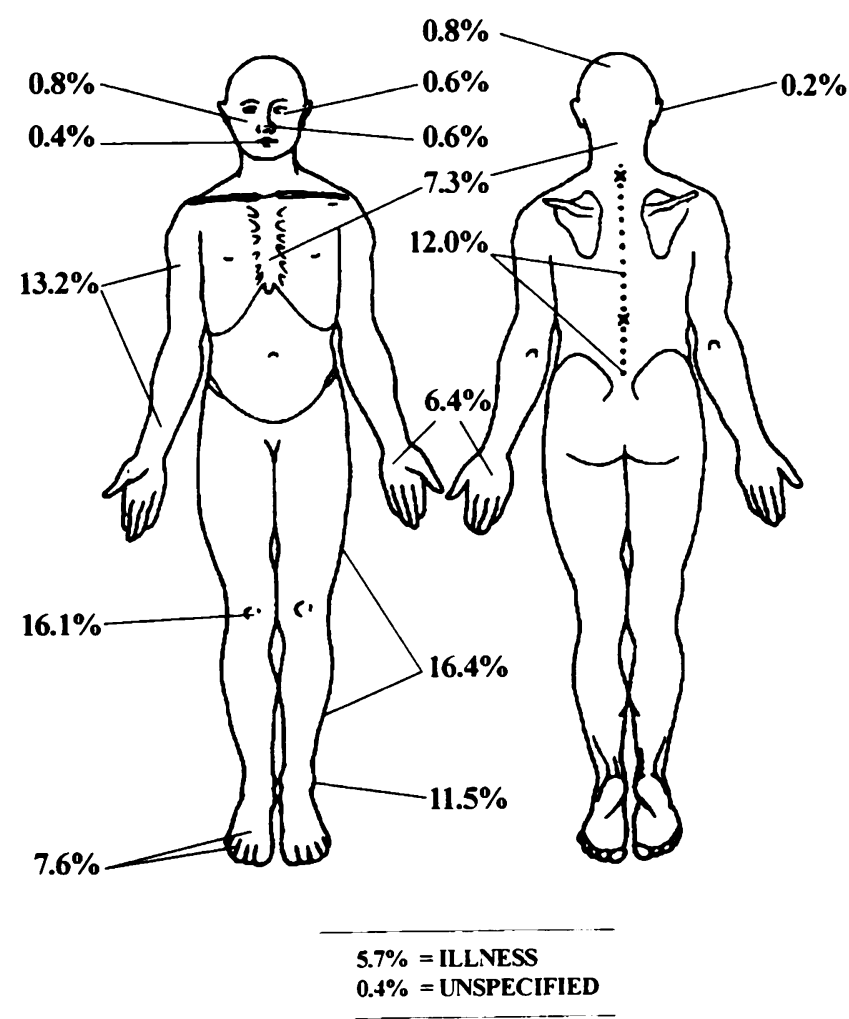

Figure 2. Anatomical distribution of exercise related morbidity sustained during vigorous activities

\section{Types of injuries}

Injuries were coded according to the International Classification of Diseases 9th revision clinical modification. ${ }^{28}$ Nearly half $(45 \%)$ of the ERM reported in the study resulted from sprains and strains, and a further $18 \%$ of the injuries were classified as 'unspecified pain' and some of these may also have been sprains and strains (Table 5). Almost half (49\%) of sprains, strains, and unspecified pain were reported as recurrent injuries. There were 41 dislocations $(2.3 \%)$, and 37 fractures $(1.8 \%)$, mainly of the bones in the hands or feet but also seven to the ribs and four to the long bones of the leg (Table 5). ERM most commonly involves the lower limb, knees, ankles, and toes. There were 63 head injuries which, however minor, are potentially serious $(3.8 \%$ of all injuries) (Figure 2). Although these were principally to the face and features there were five concussions (Table 5). There were 11 injuries to the eyes $(0.6 \%)$ and five injuries to the mouth or teeth (0.4\%) (Figure 2).

\section{Treatment providers}

Treatment was sought on at least one occasion from a third party in only one quarter of new ERM incidents. The treatment provider most likely to be contacted was the family doctor. Only $7 \%$ of the new incidents and up to $6 \%$ of recurrent injuries resulted in an attendance at a hospital accident and emergency department. Consultations with complementary medicine practioners, principally osteopaths or chiropractors, were not uncommon but despite an explicit prompt on the question-
Table 6. Treatment providers involved in ERM (all incidents)

\begin{tabular}{lrrrrr}
\hline & \multicolumn{2}{c}{ New } & & \multicolumn{2}{c}{ Recurrent } \\
\cline { 2 - 3 } \cline { 5 - 6 } $\begin{array}{l}\text { Treatment } \\
\text { provider* }\end{array}$ & $\begin{array}{c}\text { Sample } \\
\text { numbers }\end{array}$ & $\%$ & & $\begin{array}{c}\text { Sample } \\
\text { numbers }\end{array}$ & $\%$ \\
\hline Family doctor & 137 & 13.5 & & 112 & 19.1 \\
Hospital A and E & 84 & 7.0 & & 36 & 6.0 \\
$\quad$ department & 21 & 2.4 & & 13 & 2.3 \\
Other doctort & 54 & 5.0 & & 69 & 11.5 \\
Physiotherapist & 11 & 1.0 & & 3 & 0.4 \\
Other PAM & 42 & 4.1 & & 32 & 5.1 \\
Other§ & 280 & 25.4 & & 192 & 31.3 \\
All treated & 814 & 73.6 & & 419 & 68.7 \\
Not treated & & & &
\end{tabular}

$\mathrm{A}$ and $\mathrm{E}=$ accident and emergency

${ }^{*}$ More than one treatment provider was recorded for some injuries

tOther doctor includes two 'sports injury clinics'

¥Other Professions Allied to Medicine include one dentist, 10 nurses, two chiropodists, and one optician

$\S O t h e r$ includes 35 complementary medicine practitioners

naire, there was only one report of attending a dentist for ERM (Table 6). Many of the physiotherapists consulted will be practising in sports injury clinics but as this additional information was not specifically requested no reliable breakdown of attendances at sports injury clinics is possible.

\section{Discussion}

There are estimated to be 9.8 million new substantive injury incidents resulting from vigorous sports and recreational fitness activities among persons aged 16-45 years in England and Wales annually. This is approximately one per year per participant in this age group. Though large, this estimate may understate the importance of ERM since the methods used inevitably excluded reporting of injuries with severe medical consequences (such as serious spinal cord injuries ${ }^{29}$ ) and also fatal accidents. ${ }^{20}$ Nevertheless, the estimate appears to be reliable. A return rate of $68 \%$ to the postal questionnaire was achieved nationally and while this was less than in the pilot study ${ }^{20}$ the major part of the non-return was probably due to questionnaires not being received because of inaccuracies in the registers used in the sample frame. Any bias attributable to the non-return is therefore unlikely to be due to recipients not returning the form in the belief that it was not relevant to them. Bias could have arisen if exercisers or injured exercisers were less likely to receive a questionnaire than others. However, inaccuracies in FPC and GP lists are often due to the mobility of younger adults who are also more likely to participate in exercise and to sustain ERM; therefore any bias resulting from this source would be expected to deflate rather than exaggerate the estimated incidence of ERM. Nevertheless, the close correspondence between the estimated participation rates in our study and those of the GHS $^{19}$ (Table 1) indicates that any such bias is small.

An epidemiological survey in The Netherlands of 66804 persons $^{16}$ estimated that there were 2.7 million 'physical' injuries in sport each year, an average of six 
out of 10 participants annually, which is similar to that reported in our UK study. However, a study in Finland found just one acute injury per 17 adults per year in organized or unorganized sports. ${ }^{17}$ There are obvious difficulties in comparing results of different studies because of differences in study design and in the definition of sport, exercise, and injury. The list of vigorous sports and activities used in our survey (Table 1) plainly excludes some vigorous activities. To exclude cycling, for example, was wrong conceptually, but recreational cycling could not be distinguished from travel when using a mailed questionnaire.

With regard to identifying injuries, our approach was to request self reports of any injury, however minor, in the expectation that this would precipitate full reporting of all more serious injuries. A group of 'substantive' injuries was defined as those that are potentially serious (fractures, dislocations, or injuries to the head, face, or features) plus those injuries for which treatment was sought or which restricted participants from their usual activities. Of course, within this group of 'substantive' injuries many would have been of minor severity if assessed clinically. For example, almost half of the substantive injuries were sprains and strains. Nevertheless, the definition is similar to that used in the NEISS which defines an injury as an instance of trauma requiring competent medical care or resulting in at least one day of restricted activity ${ }^{\prime 23}$ and also to NAIRS which defines a 'reportable' injury or illness as one that limits athletic participation for at least the day after the day of onset, or requires substantive professional attention, or results in concussion or dental injuries. ${ }^{23}$

UK national data sources LASS ${ }^{18}$ and the GHS ${ }^{19}$ report only 'accidents with injuries' and this may exclude non-trauma morbidity as well as 'intrinsic' injuries ('injuries without accidents'). The majority of respondents to the $\mathrm{GHS}^{30}$ sought medical treatment at an accident and emergency department and less than one quarter saw only a GP. These proportions are reversed in our study. However, this discrepancy probably arises from the focus of the GHS on accidents. The majority of our respondents who only consulted their GP had 'intrinsic' injuries - principally sprains and strains and unspecified pain which may not be included within the GHS definitions. Our study also indicated a substantial number of health professionals other than GPs and accident and emergency departments are involved in treating ERM, principally physiotherapists and complementary practitioners (Table 6). Many of the physiotherapists will be based in sports injury clinics but we are unable to describe the current patterns of use of such clinics because they were not explicitly identified in the questionnaire. However, if it is assumed that anyone who sought treatment other than from an accident and emergency department might seek treatment from a sports injury clinic, then the demand for treatment at such clinics for new injuries might be for up to four million injuries per year. Even with one sports injury clinic in every District Health Authority area in England and Wales, this would result in an average of 25000 attendances at each annually which is equivalent to a small accident and emergency department.
With regard to the prevention and treatment of injuries there are a number of conclusions to be drawn. Firstly, the large annual toll of minor ERM needing only first aid and proper advice suggests that there is a need for improving or developing courses specifically for training in sports injury first aid. The importance of proper advice - for example, about management of minor ankle sprains - and informed triage (who should always attend a casualty department, who should be advised to seek help from elsewhere), is obvious.

Secondly, with regard to the risks associated with popular participation sports and activities, most injuries occur during soccer but rugby has the highest risk. The risks in rugby increase in relation to other activities as more severe or even fatal injuries ${ }^{20}$ are considered. The risk in horse riding is unusual in that the risk of the injuries recorded in our study is low and ranks alongside the risk in the racquet sports of badminton, squash and tennis, but the risk of a fatal injury is twice that of rugby. ${ }^{20}$ Research into interventions strategies to reduce the number and severity of injuries in these activities should be pursued.

Thirdly, if participation in sports and exercise is to be encouraged in order to increase the current low levels of fitness in the population, ${ }^{131}$ this encouragement should be inclined towards the less injurious activities such as the racquet sports. Finally, as most extrinsic injuries result from collisions between players, injury prevention strategies in contact sports like soccer and rugby may best be aimed at rule changes such as those that have been made in rugby union ${ }^{3233}$ and those regarding tackling from behind introduced in the 1994 soccer world cup competition. However, rule changes may be largely ineffective without improved game control and player discipline.

In conclusion, exercise related morbidity is a public health issue that reduces the potential health benefits of exercise in young, relatively fit, and economically productive populations. Recent models developed to consider the costs and benefits of exercise in the UK ${ }^{34}$ and The Netherlands ${ }^{35}$ indicate that in younger adults the costs outweigh the benefits. The reason for this is that the incidence of ERM among younger adults is large and the burden of chronic diseases is small, while in older adults the pattern is reversed. There would seem therefore to be sound economic reasons to maximize potential health gains in younger adults by setting an agenda of research priorities aimed at reducing the volume and severity of ERM and also in reviewing how ERM is managed.

\section{Acknowledgement}

The authors would like to thank the Research Unit of the Sports Council who commissioned this study. The Medical Care Research Unit is supported by the Department of Health and Trent Regional Health Authority. However, the views expressed in this report are those of the authors alone.

\section{References}

1 Fentem PH, Bassey EJ, Turnbull NB. The new case for exercise. London: The Sports Council and the Health Education Authority, 1988.

2 Report of the Royal College of Physicians. Medical aspects of 
exercise: benefits and risks. London: The Royal College Of Physicians of London, 1991.

3 US Department of Health, Education and Welfare. Healthy people: the Surgeon General's report on health promotion and disease prevention. DHEW Pub No. (PHS) 7955071. Washington DC: Public Health Service, Government Printing Office, 1979.

4 World Health Organisation Targets for health for all. Copenhagen: Regional Office for Europe, 1985.

5 Matheson J. Participation in sport. General Household Survey 1987. Office of Population Censuses and Surveys, Social Survey Division. Series GHS no 17 supplement B. London: HMSO, 1990

6 Allied Dunbar national fitness survey: a report on activity patterns and fitness levels. Main findings. London: Sports Council and Health Education Authority, 1992.

7 The 'double tackle' - another cause of serious cervical spinal injury in rugby players. Case reports. S Afr Med Tydskrif 1983 64 : $595-6$.

8 Jones NP, Tullo AB. Severe eye injuries in cricket. Br J Sports Med 1986; 20 : 178-9.

9 Bedford PJ, Macauley DC. Attendances at a casualty department for sport related injuries. Br J Sports Med 1984; 18: 116-21.

10 Watters DAK, Brooks S, Elton A, Little K. Sports injuries in an accident and emergency department. Arch Emerg Med 1984; 2 : 105-12.

11 Deveraux MD, Lachmann S. Athletics attending a sports clinic-a review. Br J Sport Med 1983; 17 : 147-42.

12 Forward GR. Indoor cricket injuries. Med J Aust 1988; 148: $560-61$.

13 Lindner KJ, Caine DJ. Injury patterns of female competitive club gymnasts. Can J Sports Sci 1990; 15 : 254-61.

14 Nicholl JP, Williams BT. Medical problems before and after popular marathon. BMJ 1982; 285 : 1465-6.

15 Kallinen $M$, Alen M. Sports-related injuries in elderly men still active in sports. Br J Sports Med 1994; 28 : 52-5.

16 Van Galen WCHW, Diedericks J. Sports injuries in The Netherlands. Report from the Institute of Sports Medicine at the University of Limburg, 1988.

17 Sandelin J, Santavirta S, Lattila R, Vuolle P, Sarna S. Sports injuries in a large urban population: occurrence and epidemiological aspects. Int J Sports Med 1984; 8: 61-6.

18 Department of Trade and Industry. Home and Leisure Accident Research. Twelfth Annual Report: Home Accident Surveillance System, 1988 data. London: Consumer Safety Unit, Department of Trade and Industry, 1993

19 Office of Population Censuses and Surveys. General Household
Survey 1987. Social Survey Division. Series GHS no 17, London: HMSO, 1989.

20 Nicholl JP, Coleman P, Williams BT. Injuries in sports and exercise: main report. London: Sports Council, 1993.

21 Nicholl JP, Coleman P, Williams BT. Pilot study of the epidemiology of sports injuries and related morbidity. $\mathrm{Br} J$ Sports Med 1991; $25: 61-6$.

22 Craig JA. Socio-economic classification of local and health authorities of Great Britain. Office of Population Censuses and Surveys studies on medical and population subject. No 48. London: HMSO, 1987.

23 Damien CF, Heorner EF, Shaw JL. Injury surveillance systems for sports. In: Vinger PR, Heorner EF, eds. Sports injuries: the unthwarted epidemic, 2nd ed. Littleton, USA: PSG Publishing Co, 1986.

24 Butcher R, Elliott D. A sampling errors manual. Office of Population Censuses and Surveys, Social Survey Division, London: HMSO, 1990.

25 Fraser RC, Clayton DG. The accuracy of age-sex registers, practice medical records and family practitioner committee registers. J $R$ Coll Gen Pract 1981; 31: 410-9.

26 McEwan J, King W, Bickler J. Attendance and non-attendance for breast screening service. BMJ 1989; 299 : 104-6.

27 Beardow R, Oerton J, Vitor C. Evaluation of the cervical cytology screening programme in an inner city health district. BMJ 1989; 299: 98-100.

28 US Department of Health and Human Services. The international classification of diseases - 9 th revision-clinical modification. Volumes 1-3, 2nd edition. Washington DC: US Department of Health and Human Services, September 1980.

29 Silver JR. Spinal injuries in sports in the UK. Br J Sports Med 1993 27: 115-20.

30 Breeze T, Trevor G, Milmont A. 1989 General Household Survey. Office of Population Censuses and Surveys. Series GHS no 20. London: HMSO, 1991.

31 Exercise. Why bother? Look after your heart campaign. London Health Education Authority.

32 Silver JR. Injuries of the spine sustained during rugby. $\mathrm{Br} J$ Sports Med 1992; 26: 253-8.

33 Burry HC, Calcinai CJ. The need to make rugby safer. BMJ 1988 ; 296: 149-50.

34 Nicholl JP, Coleman P, Brazier JE. Health and healthcare costs and benefits of exercise. Pharmaco Economics 1994; 5 : 109-22.

35 Reijner J, Velthuijsen JW. Economic aspects of health through sport. In: Conference Proceedings: Sports an Economic Force in Europe. Lilleshall UK. November 1989, pp. 76-90. 